\title{
Manometry performed at indwelling pleural catheter insertion to predict unexpandable lung
}

\author{
Paul J. Halford ${ }^{1,2}$, Rahul Bhatnagar ${ }^{1,2}$, Paul White ${ }^{3}$, Mohammed Haris ${ }^{4}$, Richard N. Harrison ${ }^{5}$ \\ Jayne Holme $^{6}$, Pasupathy Sivasothy ${ }^{7}$, Alex West ${ }^{8}$, Lesley J. Bishop ${ }^{9}$, Andrew E. Stanton ${ }^{10}$, \\ Mark Roberts ${ }^{11}$, Clare Hooper ${ }^{12}$, Nick A. Maskell ${ }^{1,2}$
}

${ }^{1}$ Academic Respiratory Unit, University of Bristol, Bristol, UK; ${ }^{2}$ North Bristol NHS Trust, Bristol, UK; ${ }^{3}$ University of the West of England, Bristol, UK; ${ }^{4}$ University Hospital of North Midlands NHS Trust, Stoke-on-Trent, UK; ${ }^{5}$ North Tees and Hartlepool NHS Foundation Trust, Stocktonon-Tees, Manchester, UK; ${ }^{6}$ Manchester University NHS Foundation Trust, Manchester, UK; ${ }^{7}$ Cambridge University Hospitals NHS Foundation Trust, Cambridge, UK; ${ }^{8}$ Guy's and St. Thomas' NHS Foundation Trust, London, UK; ${ }^{9}$ Portsmouth Hospitals NHS Trust, Portsmouth, UK; ${ }^{10}$ Great Western Hospitals NHS Foundation Trust, Swindon, UK; ${ }^{11}$ Sherwood Forest Hospitals NHS Foundation Trust, Sutton-in-Ashfield, UK;

${ }^{12}$ Worcester Acute Hospitals NHS Trust, Worcester, UK

Contributions: (I) Conception and design: R Bhatnagar, NA Maskell; (II) Administrative support: None; (III) Provision of study materials or patients: None; (IV) Collection and assembly of data: R Bhatnagar, NA Maskell, M Haris, RN Harrison, J Holme, P Sivasothy, A West, LJ West, AE Stanton, M Roberts, C Hooper; (V) Data analysis and interpretation: PJ Halford, R Bhatnagar, NA Maskell, P White; (VI) Manuscript writing: All authors; (VII) Final approval of manuscript: All authors.

Correspondence to: Paul J. Halford. Academic Respiratory Unit, $2^{\text {nd }}$ Floor Learning and Research Building, Southmead Hospital, Bristol, BS10 5NB, UK. Email: Paul.Halford@bristol.ac.uk.

Background: The finding of unexpandable lung (UL) at an early timepoint is of increasing importance in guiding treatment decisions in patients with malignant pleural effusion (MPE). Pleural manometry is the most common technique to delineate UL, however it has never been measured via an indwelling pleural catheter (IPC). To further the evidence base we analysed all patients in the IPC-PLUS study who had manometry performed during IPC insertion for the ability to predict substantial UL using manometry.

Methods: All patients enrolled in IPC-PLUS who had manometry performed at IPC insertion and radiographic assessment of UL at day 10 were included. Elastance curves were visually inspected for each patient. Initial pleural pressure, closing pleural pressure, and terminal elastance were analysed for their differences and predictive ability in those with substantial UL, defined as $\geq 25 \%$ entrapment on chest radiography.

Results: A total of 89 patients had manometry performed at IPC insertion with subsequent radiographic assessment of UL and interpretable elastance curves. Those with substantial UL had a significantly lower median closing pleural pressure $\left(-15.00\right.$ vs. $\left.0.00 \mathrm{cmH}_{2} \mathrm{O}, \mathrm{P}=0.012\right)$ and higher terminal elastance $(12.03$ vs. $8.59 \mathrm{cmH}_{2} \mathrm{O} / \mathrm{L}, \mathrm{P}=0.021$ ) compared to a combined group with no or partial UL. However, the predictive ability of these factors to discriminate substantial UL was poor, with areas under the receiver operating characteristic curves of 0.695 and 0.680 for closing pleural pressure and elastance respectively.

Conclusions: Our results suggest that manometry is not useful in accurately predicting substantial UL when used via an IPC at the time of insertion.

Keywords: Malignant pleural effusion (MPE); pleural manometry; indwelling pleural catheter (IPC)

Submitted Jul 29, 2019. Accepted for publication Nov 08, 2019.

doi: $10.21037 /$ jtd.2020.02.25

View this article at: http://dx.doi.org/10.21037/jtd.2020.02.25 


\section{Introduction}

Malignant pleural effusion (MPE) affects at least 150,000 patients per year in the US alone (1), often recurring after drainage and leading to debilitating dyspnoea. The finding of substantial unexpandable lung (UL) at an early timepoint in these patients is of increasing importance in guiding treatment decisions. Traditionally, those with adequate pleural apposition are eligible for inpatient talc pleurodesis $(2,3)$ whilst those with UL, also sometimes referred to as 'trapped', 'entrapped' or 'non-expansile' lung, underwent repeated drainage and/or ambulatory management using an indwelling pleural catheter (IPC) (4). IPCs, however, are increasingly inserted first line in response to patient choice, even in those without evidence of UL $(5,6)$. The recent IPC-Plus trial, which examined the use of outpatient talc pleurodesis via an IPC for MPE, showed this combination approach achieved better pleurodesis than IPC alone in those without substantial UL (7).

UL, and its severity, may be suggested by hydropneumothorax or a persistent fluid collection on chest radiography following effusion drainage, with patients also potentially experiencing excessive cough or central chest pain during aspiration. These findings, however, may not become apparent until after definitive treatment begins. Real-time pleural manometry during thoracentesis has been advocated as a method of identifying UL earlier (8). However, pulmonologists continue to disagree over its clinical utility (9), sensitivity $(10,11)$ and the specific manometry values which delineate between 'normal' and UL (10-12).

As part of the IPC-Plus study, pleural manometry was performed during IPC insertion in a proportion of patients as part of a pre-planned exploratory sub-study, and we report the results here (13). The aims of the sub-study were twofold: firstly, to assess the utility of manometry measured via IPC at the time of insertion to predict substantial UL, which could help guide patient management in the future, specifically with regards to later talc instillation; and secondly to add further evidence to clarify the efficacy of pleural manometry more generally.

\section{Methods}

\section{Trial participants}

Patients were eligible for the main IPC-Plus study if they had a symptomatic MPE which was suitable for treatment with an IPC, had an expected survival of 2 months or more, and an Eastern Cooperative Oncology Group performance status of 3 or better. Patients with known pre-existent UL were excluded from trial entry (7). Ethics approval for recruitment was obtained from the South Central (Oxford A) Research Ethics Committee (approval number: 12/SC/0242).

\section{UL categorisation}

IPCs were inserted using standard technique with patients supine. After 10 days of ambulatory drainage, chest radiography was performed to evaluate the presence and degree of UL and subsequent suitability for randomization (13). Persisting fluid collection despite ambulatory drainage and/or evidence of hydropneumothorax were felt to represent underlying UL. Those with an estimated degree of UL exceeding $25 \%$ of the hemithorax (i.e., less than $75 \%$ pleural apposition) were excluded from further participation in the main trial.

For the purpose of the analysis described here, radiographic degree of UL at day 10 was assessed by two independent clinicians and was considered the diagnostic standard. Patients were divided into three groups: (I) those with no discernible UL (No-UL); (II) those with partial UL (P-UL, affecting $<25 \%$ of the hemithorax); and (III) those with substantial UL (S-UL, affecting $\geq 25 \%$ of the hemithorax).

\section{Use of manometry via IPCs}

The measurement of pleural pressure at insertion, via the IPC drainage circuit, was recommended in the study protocol, but was ultimately left at the discretion of the local investigator. Pleural pressure was assessed using a commercially-available, single-use digital manometer (Mirador Biomedical) (14). Operators followed a standardised operating procedure (see online supplement: http://fp.amegroups.cn/cms/68c570d3db37deab671bc3 7 f9b2b6445/jtd.2020.02.25-1.pdf) and were instructed to sit the patient up post-IPC insertion to perform manometry, to increase the chances of the drain sitting in the dependent portion of fluid. Measurements were taken at the level of the IPC entering the pleural cavity and endexpiratory pressures were recorded. As movement during measurement can cause false readings the pressure recorded at each volume required consistency by obtaining the same value over a minimum of four patient breaths. An endexpiratory reading was taken immediately after insertion, before any fluid removal, and this was recorded as the 


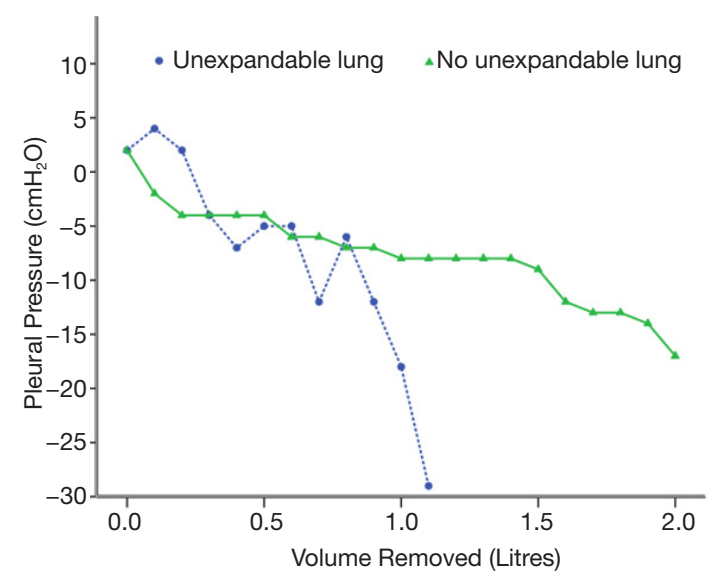

Figure 1 An example of the pleural pressure/volume (elastance) curves generated for a patient without unexpandable lung (green) and another with unexpandable lung (blue).

initial pleural pressure. Operators were given the option to record subsequent readings after every 100 or $200 \mathrm{~mL}$ of fluid removed. The total volume drained immediately after insertion was left at the discretion of the operator. As many patients weren't drained to 'dryness' during catheter insertion, the final pressure measurement did not necessarily reflect the pressure of the fully drained hemithorax.

To avoid lung deformation forces potentially affecting final pleural pressure measurements, the 'closing pleural pressure' was documented as the last pressure recorded with subsequent drainage of at least $30 \mathrm{~mL}$. Operators were advised to consider terminating aspiration in the event of significant chest pain or cough; an end-expiratory pleural pressure reading of $-20 \mathrm{cmH}_{2} \mathrm{O}$ or lower; or if no further drainage could be achieved.

\section{Pleural pressure and manometry graph analysis}

Manometry recordings were used to generate graphs of pressure against volume (elastance curves, Figure 1) for each patient. These elastance curves were assessed and categorized by two pulmonologists who remained blind to all clinical data and previous radiographic assessments of UL. Using previously-described parameters (15), each graph was assigned to one of the following groups, which aimed to further characterise the nature of the UL (if present): a shallow monophasic curve (representing no discernible UL); a steep monophasic curve (representing a largely fixed, 'trapped lung'); or a biphasic curve (representing 'lung entrapment' with some initial capacity for lung expansion). For biphasic curves, both assessors agreed upon an inflection point. To quantify elastance, curves were divided into up to three distinct portions using a previously described method (12). Terminal elastance was calculated using linear regression of monophasic curves, or the section following the inflection point for biphasic curves. If curves had fewer than 4 manometric readings or if both blinded assessors couldn't discern any consistent pattern to allow analysis, then these results were excluded from further analysis.

\section{Statistical methods}

All statistical tests were performed using IBM SPSS Statistics Version 23 (Armonk, NY, USA). Differences in initial pleural pressure, closing pleural pressure and terminal elastance were compared between the radiographic groups described above. Additionally, for consistency with the original trial's methods and to reflect clinical relevance, the radiographic categories where talc pleurodesis was not contraindicated (No-UL and $\mathrm{P}-\mathrm{UL}$ ) were combined to form a separate group (No+P-UL) for comparison against categories in which talc pleurodesis was contraindicated (S-UL).

Descriptive statistics were performed to evaluate baseline differences between participants undergoing manometry. The Chi-squared test was used for categorical variables and Mann Whitney $U$ test for continuous variables. For comparisons between independent radiographic groups the Jonckheere-Terpstra Test for ordered alternatives was used, and for two-group comparisons Mann-Whitney $\mathrm{U}$ tests were used. An $\alpha$ value of 0.05 was taken as statistically significant.

Factors demonstrating significance between the combined group of No+P-UL compared to S-UL were assessed for ability to predict substantial lung entrapment using receiver operating characteristic (ROC) curves. Cutoff values were extracted using a combination of Youden's index and visual inspection of the ROC curve. We also used our dataset to attempt to validate previously-reported elastance values used to delineate UL (10-12).

\section{Results}

Of the 250 patients enrolled into IPC-Plus (7), 113/250 $(45 \%)$ at $13 / 18$ recruitment centres had manometry performed. Baseline characteristics between those having and not having manometry performed at IPC insertion are shown in Table 1. Patients undergoing manometry had 


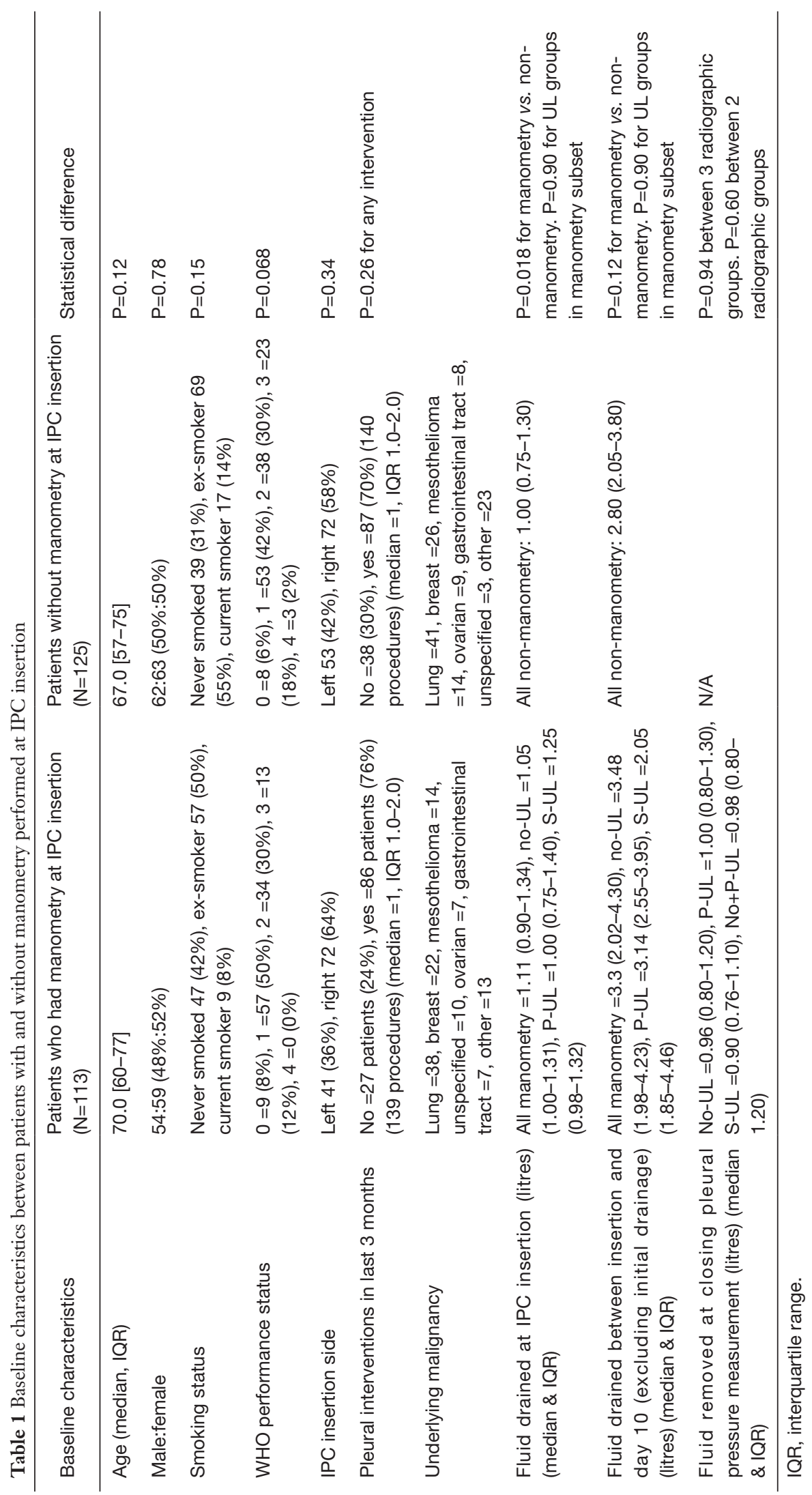




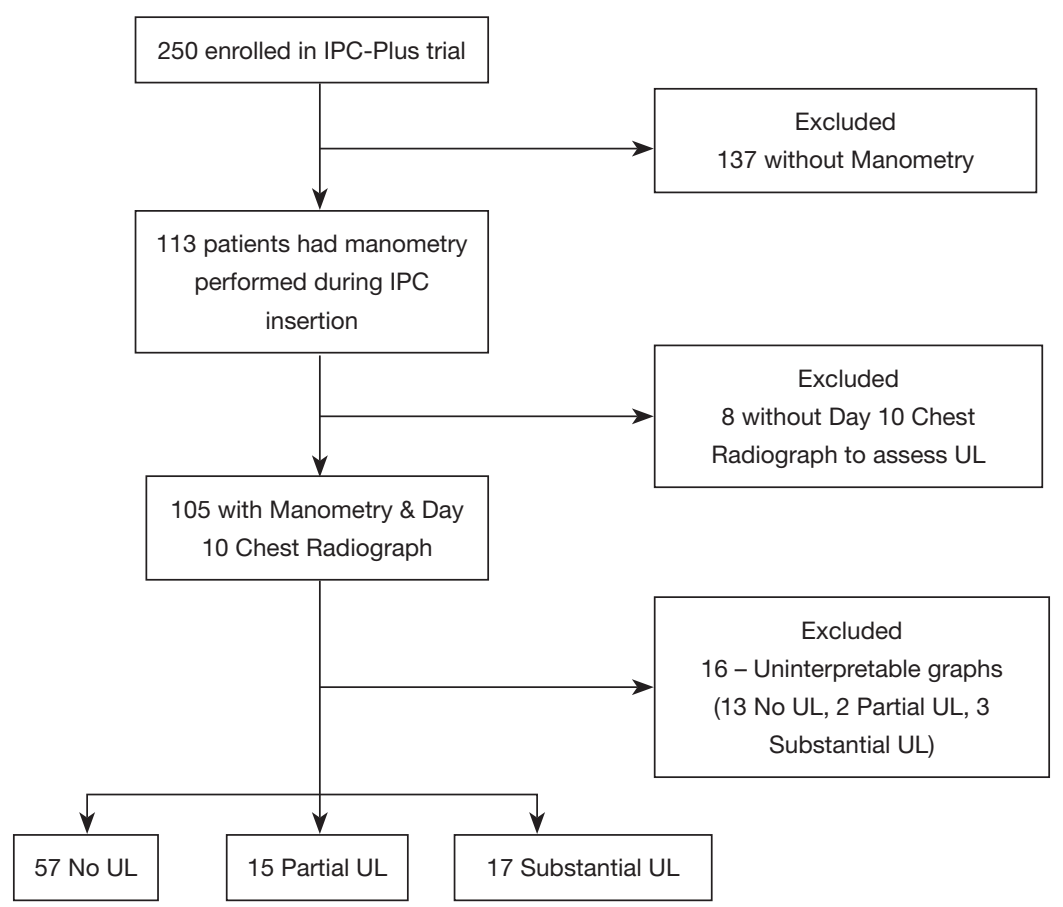

Figure 2 Flow diagram of categorisation of patients into individual manometric groups. UL, unexpandable lung; IPC, indwelling pleural catheter.

a greater median amount of fluid removed during their initial drainage (1.11 L, IQR 0.90-1.34 L vs. $1.00 \mathrm{~L}$, IQR $0.75-1.40 \mathrm{~L}, \mathrm{P}=0.018)$, but no other significant baseline differences were observed.

Eight patients were excluded having withdrawn from the study prior to day 10 assessment, meaning 105/250 (42\%) were assessed radiographically for UL. Following visual inspection of manometry curves, 16 patients were deemed to have uninterpretable data, leaving 89/250 (36\%) (Figure 2).

\section{Initial pleural pressure to assess $U L$}

There was no difference in median initial pleural pressure between any of the three radiographic groups when compared individually (No-UL $=5.50 \mathrm{cmH}_{2} \mathrm{O}$, IQR $0.00-+12.25 \mathrm{~cm} \mathrm{H}_{2} \mathrm{O}, \mathrm{P}-\mathrm{UL}$ $=4.00 \mathrm{~cm} \mathrm{H}_{2} \mathrm{O}, \mathrm{IQR}-2.00-+16.00 \mathrm{cmH}_{2} \mathrm{O}, \mathrm{S}-\mathrm{UL}$ $=2.00 \mathrm{cmH}_{2} \mathrm{O}, \mathrm{IQR}-1.50-+8.50 \mathrm{cmH}_{2} \mathrm{O}, \mathrm{P}=0.288$ ), or when the No-UL and P-UL groups were combined and compared to S-UL (No+P-UL $=5.00 \mathrm{cmH}_{2} \mathrm{O}, \mathrm{IQR}$ $0.00-+13.00 \mathrm{cmH}_{2} \mathrm{O}, \mathrm{S}-\mathrm{UL}=2.00 \mathrm{cmH}_{2} \mathrm{O}, \mathrm{IQR}-1.50-$ $+8.50 \mathrm{cmH}_{2} \mathrm{O}, \mathrm{P}=0.267$ ).

\section{Closing pleural pressure to assess $U L$}

There were significant differences in median closing pleural pressures between the three radiographic groups (No-UL $=0.00 \mathrm{cmH}_{2} \mathrm{O}, \mathrm{IQR}-12.5-+6.50 \mathrm{cmH}_{2} \mathrm{O}, \mathrm{P}-\mathrm{UL}$ $=-10.00 \mathrm{cmH}_{2} \mathrm{O}, \mathrm{IQR}-21.00-+9.00 \mathrm{cmH}_{2} \mathrm{O}, \mathrm{S}-\mathrm{UL}$ $=-15.00 \mathrm{cmH}_{2} \mathrm{O}, \mathrm{IQR}-27.00--1.00 \mathrm{cmH}_{2} \mathrm{O}, \mathrm{P}=0.010$, Table 2). On pairwise comparisons, this difference occurred between the groups No-UL and S-UL $(\mathrm{P}=0.012)$. A significant difference persisted when comparing the combined $\mathrm{No}-\mathrm{UL}+\mathrm{P}-\mathrm{UL}$ group to $\mathrm{S}-\mathrm{UL}(\mathrm{No}+\mathrm{P}-$ $\mathrm{UL}=0.00 \mathrm{cmH}_{2} \mathrm{O}, \mathrm{IQR}-14.75-+6.75 \mathrm{cmH}_{2} \mathrm{O}, \mathrm{S}-\mathrm{UL}$ $=-15.00 \mathrm{cmH}_{2} \mathrm{O}, \mathrm{IQR}-27.00--1.00 \mathrm{cmH}_{2} \mathrm{O}, \mathrm{P}=0.012$, Figure 3).

The ability of closing pleural pressure to predict radiographic S-UL as opposed to the combined $\mathrm{No}+\mathrm{P}-$ UL group was assessed. The ROC curve generated an area under the curve (AUC) of 0.695 and a closing pressure of $-20.5 \mathrm{cmH}_{2} \mathrm{O}$ was extrapolated to predict UL (see Table 3 and Figure 4). This value identified 6/17 (35\%) of those with S-UL with five false positive results, giving a positive predictive value of $6 / 11$ (55\%). It correctly identified $67 / 72$ (93\%) patients without S-UL. 
Table 2 Manometry values in individual radiographically defined groups of unexpandable lung severity. No+P-UL represents a combined group of No-UL plus P-UL

\begin{tabular}{lccccc}
\hline Measurement & No-UL & P-UL & No+P-UL & S-UL & Significant difference \\
\hline Initial pleural pressure & 5.50 & 4.00 & 5.00 & 2.00 & $3 \mathrm{groups}^{\star} \mathrm{P}=0.288$, \\
(median \& IQR) $\left(\mathrm{cmH}_{2} \mathrm{O}\right)$ & $(0.00-+12.25)$ & $(-2.00-+16.00)$ & $(0.00-+13.00)$ & $(-1.50-+8.50)$ & $2 \mathrm{groups}^{\star *} \mathrm{P}=0.267$ \\
Closing pleural pressure & 0.00 & -10.00 & 0.00 & -15.0 & $3 \mathrm{groups}^{\star} \mathrm{P}=0.010$, \\
(median \& IQR) $\left(\mathrm{cmH}_{2} \mathrm{O}\right)$ & $(-12.5-+6.50)$ & $(-21.00-+9.00)$ & $(-14.75-+6.75)$ & $(-27.00--1.00)$ & $2 \mathrm{groups}^{\star *} \mathrm{P}=0.012$ \\
Terminal elastance $($ median & 8.00 & 9.00 & 8.59 & 12.03 & $3 \mathrm{groups}^{\star} \mathrm{P}=0.022$, \\
\& IQR) $\left(\mathrm{cmH}_{2} \mathrm{O} / \mathrm{L}\right)$ & $(4.76-11.79)$ & $(6.25-15.22)$ & $(5.54-12.12)$ & $(7.42-34.5)$ & 2 groups $^{\star *} \mathrm{P}=0.021$ \\
\hline
\end{tabular}

*, comparison between groups No-UL, P-UL and S-UL; **, comparison between groups No+P-UL and S-UL. IQR, interquartile range.

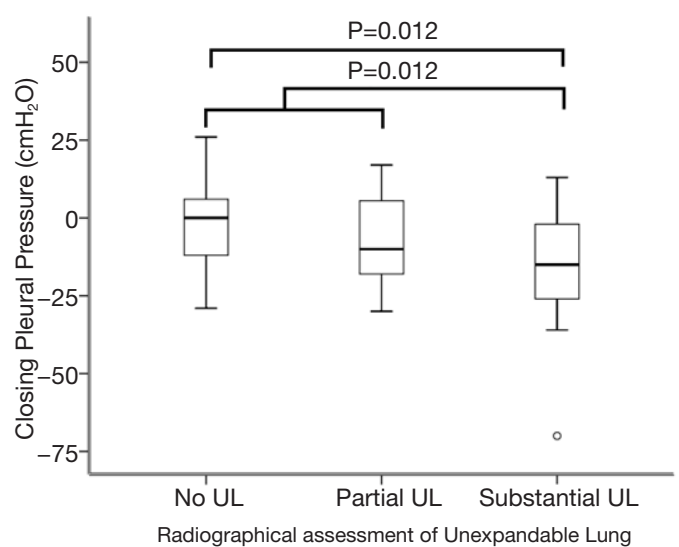

Figure 3 Differences in closing pleural pressure between different radiographically-defined groups of unexpandable lung severity. UL, unexpandable lung.

\section{Terminal elastance to assess $U L$}

Terminal elastance and closing pleural pressure were significantly correlated (Pearson correlation -0.650 , $\mathrm{P}<0.001)$. When using terminal elastance to predict radiographic $U L$, there were significant differences between the 3 groups (No-UL $=8.00 \mathrm{cmH}_{2} \mathrm{O} / \mathrm{L}$, IQR 4.76$11.79 \mathrm{cmH}_{2} \mathrm{O} / \mathrm{L}, \mathrm{P}-\mathrm{UL}=9.00 \mathrm{cmH}_{2} \mathrm{O} / \mathrm{L}, \mathrm{IQR} 6.25-$ $15.22 \mathrm{cmH}_{2} \mathrm{O} / \mathrm{L}, \mathrm{S}-\mathrm{UL}=12.03 \mathrm{cmH}_{2} \mathrm{O} / \mathrm{L}, \mathrm{IQR} 7.42-$ $\left.34.5 \mathrm{cmH}_{2} \mathrm{O} / \mathrm{L}, \mathrm{P}=0.022\right)$. Pairwise comparisons showed this occurred between the groups No-UL and S-UL $(\mathrm{P}=0.027)$. Comparing the combined No+P-UL group with the S-UL group also yielded a significant difference $(\mathrm{No}+\mathrm{P}-\mathrm{UL}$ $=8.59 \mathrm{cmH}_{2} \mathrm{O} / \mathrm{L}, \mathrm{IQR}$ 5.54-12.12 $\mathrm{cmH}_{2} \mathrm{O} / \mathrm{L}, \mathrm{S}-\mathrm{UL}$ $=12.03 \mathrm{cmH}_{2} \mathrm{O} / \mathrm{L}, \mathrm{IQR} 7.42-34.5 \mathrm{cmH}_{2} \mathrm{O} / \mathrm{L}, \mathrm{P}=0.021$, Table 2).

When assessing the ability of elastance to predict S-UL the ROC curve generated an AUC of 0.680 (Figure 4). Using an extrapolated value of $27.3 \mathrm{cmH}_{2} \mathrm{O} / \mathrm{L}$ to predict
UL, 5/17 (29.4\%) cases were correctly predicted, with four false positive results, giving a positive predictive value of 5/9 (56\%). And, 68/72 (94\%) patients without S-UL were correctly predicted using this cut-off (Table 3).

\section{Discussion}

To our knowledge, this is the first study to describe the assessment of pleural pressure measured via an IPC at the time of insertion. We aimed to assess the feasibility of this technique and, being one of the largest published datasets on pleural manometry, also further the knowledge base in this area. Whilst we do not necessarily envisage manometry results collected via an IPC to be different to conventional methods, it is important to note this technique has not been validated or compared with usual methods.

As a result of the IPC-Plus study, early outpatient administration of talc through an IPC is likely to become increasingly common (7). In this setting, pre-emptive identification of substantial UL could potentially avoid both the inconvenience of the additional hospital visit needed to perform radiography, as well as the potential discomfort associated with talc instillation, which is less likely to be successful.

Elastance is the commonest measurement used to infer the presence of UL (10-12). Our results show a significant difference in elastance between those with substantial UL and those with no or partial $(<25 \%) \mathrm{UL}(\mathrm{P}=0.021)$. Whilst radiological definitions of UL often differ, our results are broadly consistent with other studies reporting higher elastance in those with UL $(11,16)$. We also found no difference in the initial pleural pressure between any groups tested, a result previously described elsewhere (16).

In general, the use of closing pleural pressure in predicting UL is less commonly reported in the literature, 
Table 3 Ability of different manometry values to predict substantial unexpandable lung on subsequent chest radiography

\begin{tabular}{lcccc}
\hline $\begin{array}{l}\text { Method to predict } \\
\text { unexpandable lung }\end{array}$ & $\begin{array}{c}\text { Area under the } \\
\text { receiver operating } \\
\text { characteristic curve }\end{array}$ & Sensitivity $(95 \% \mathrm{Cl})$ & $\begin{array}{c}\text { Specificity }(95 \% \mathrm{Cl}) \\
\begin{array}{c}\text { Positive predictive } \\
\text { value }(95 \% \mathrm{Cl})\end{array}\end{array} \begin{array}{c}\text { Negative predictive } \\
\text { value }(95 \% \mathrm{Cl})\end{array}$ \\
\hline $\begin{array}{l}\text { Closing pleural pressure } \\
<-20.5 \mathrm{cmH}_{2} \mathrm{O}\end{array}$ & 0.695 & $0.35(0.14-0.62)$ & $0.93(0.85-0.98)$ & $0.55(0.23-0.83)$ \\
$\begin{array}{l}\text { Terminal Elastance } \\
>27.3 \mathrm{CmH}_{2} \mathrm{O} / \mathrm{L}\end{array}$ & 0.680 & $0.29(0.10-0.56)$ & $0.94(0.86-0.99)$ & $0.56(0.21-0.86)$ \\
$\begin{array}{l}\text { Terminal Elastance } \\
>19.0 \mathrm{cmH}_{2} \mathrm{O} / \mathrm{L}\end{array}$ & 0.680 & $0.35(0.14-0.62)$ & $0.86(0.76-0.93)$ & $0.38(0.15-0.65)$ \\
$\begin{array}{l}\text { Terminal Elastance } \\
>14.5 \mathrm{cmH}_{2} \mathrm{O} / \mathrm{L}\end{array}$ & 0.680 & $0.41(0.18-0.67)$ & $0.80(0.70-0.89)$ & $0.33(0.15-0.57)$ \\
\hline
\end{tabular}

$\mathrm{Cl}$, confidence interval.

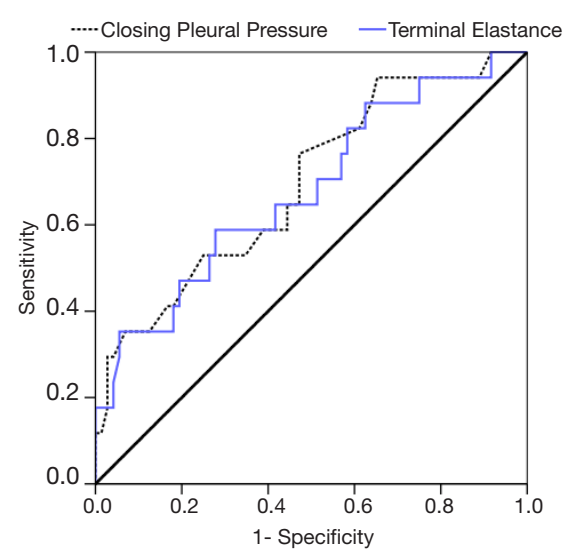

Figure 4 Receiver operating characteristic curve for the ability of closing pleural pressure and terminal elastance to predict substantial unexpandable lung.

despite previously being used to facilitate safe drainage during thoracentesis (17). We found significant differences between the radiographic groups No-UL and S-UL in the median closing pleural pressure. This effect persisted when comparisons were made between those with S-UL and a combined group of patients with No-UL or P-UL. Our finding supports work from a previously-reported small series where a trend for significance was found whereby those with UL had lower closing pleural pressures (16).

We noted similar predictive abilities of closing pleural pressure and elastance in delineating substantial UL, yielding areas under the ROC curve of 0.695 and 0.680 respectively, with the latter result similar to another study in which elastance had an area under the ROC curve of 0.69 for predicting UL in 34 patients (10). However, closing pressure may actually be a more attractive predictor of UL than elastance in clinical practice, with the latter requiring multiple measurements to be taken and charted.

Additionally, our extrapolated closing pleural pressure cut-off value of $-20.5 \mathrm{cmH}_{2} \mathrm{O}$ is similar to the recommended value of $-20.0 \mathrm{cmH}_{2} \mathrm{O}$ commonly used to guide termination of therapeutic aspiration due to unsafe pleural pressures (17). The 6/11 (55\%) patients who had a closing pleural pressure $<-20 \mathrm{cmH}_{2} \mathrm{O}$ had substantial UL, implying that if pressures are being monitored at thoracentesis to facilitate safe drainage, a value of $-20 \mathrm{cmH}_{2} \mathrm{O}$ may identify an unsafe drainage pressure, possibly due to the increased likelihood of underlying UL. However, recently published work has shown that the patient-derived benefit of using manometry to facilitate safe drainage is limited, which may lead to its decreasing use for this indication (18).

In general, however, the predictive ability of both elastance and closing pleural pressure was poor. Whilst specificity was $94 \%$ and $93 \%$ for an elastance $>27.3 \mathrm{cmH}_{2} \mathrm{O} / \mathrm{L}$ and closing pressure $<-20.5 \mathrm{cmH}_{2} \mathrm{O}$ respectively, sensitivity at these values was $29 \%$ and $35 \%$. Likewise, when using our series to validate traditional manometric cut-offs reported in the literature (10-12), we observed similar results with a sensitivity of $35 \%$ for an elastance of $>19 \mathrm{cmH}_{2} \mathrm{O} / \mathrm{L}$ to predict UL (Table 3). This is similar to findings of a $40 \%$ sensitivity for an elastance of $>19 \mathrm{cmH}_{2} \mathrm{O} / \mathrm{L}$ to predict radiographical UL previously reported elsewhere (10), suggesting that some patients with substantial UL have 'normal' elastance (12). However, this is not consistently seen in the literature (11), perhaps due to differing diagnostic criteria for substantial UL. Some authors previously classified UL as post- 
thoracentesis pneumothorax in 'most places' of the hemithorax (11), whereas others only required postthoracentesis pneumothorax confined to the lower lobe (10). As manometry is a reflection of pleural pressure in the whole hemithorax, if diagnosis is based on a segment of the hemithorax only, the drastic pressure changes associated with unexpandable areas are likely to be dampened by the less pronounced changes in normal areas of expansion (10). Different definitions of UL, therefore, are likely to affect the predictive ability of manometry. Our definition of substantial UL is different from other studies, which may reflect why we observed a better predictive value with a different elastance cut-off value $\left(27.3 \mathrm{cmH}_{2} \mathrm{O} / \mathrm{L}\right)$ than those traditionally used. However, overall, neither the cut-off values of elastance or closing pleural pressure extrapolated from our results, nor the traditionally used elastance values, had particularly good predictive properties using our dataset, limiting their clinical utility.

Major strengths of this study include its large sample size compared to previous publications $(10,11,16)$, and the pragmatic populations of patients and investigators taking measurements. The latter is of particular interest since a commonly perceived barrier to widespread manometry use has been its applicability outside of specialist centres. We also used radiographically-defined UL as our comparator, something not consistently performed in studies reporting manometry $(19,20)$. Additionally, radiographs were taken after a period of regular drainage, reducing the likelihood that UL would be obscured by residual fluid. On average patients had over 4 litres drained prior to radiographic assessment, whereas other studies often assess for UL following a single drainage of approximately 1 litre $(21,22)$.

There are some limitations to this study, primarily arising because these data comprise an exploratory subset analysis from another study. As not all patients enrolled in the parent study had manometry performed at IPC insertion this may have introduced a degree of selection bias, although we feel it unlikely that this will have had a significant effect on our results. Firstly, known significant UL based on prior radiology was an exclusion criterion for enrolment. Furthermore, there are limited useful predictors of UL prior to drainage, and as Table 1 highlights patients having manometry performed had similar characteristics to those that did not.

We used a single-use digital manometer to measure pleural pressures, whilst more sophisticated methods are available, such as electronic manometers (14), this was not felt to be practical in a multi-centred study nor reflective of what could be achieved in clinical practice outside of a few specialist sites. In fact, digital manometers have been shown to correlate well with these more sophisticated techniques (14). However their use via an IPC has not been validated, with this approach technically more complex than during standard thoracentesis. Additionally, due to the pragmatic nature of the IPC-Plus study, it is likely that operators in our study had less experience in manometry when compared to those with research interests in this area or for whom manometry is a routine technique.

As initial drainage using manometry was not continued to 'dryness', and residual fluid remaining after initial drainage was not quantified, this may underestimate the number with UL predicted by manometry. This is an inherent limitation of our methodology as our aim was to facilitate safe regular ambulatory drainage with a view to then undergo pleurodesis rather than undertake large-volume drainage at insertion. However, to our knowledge, only one study has attempted full drainage whilst assessing for residual fluid, using manometry to facilitate safe large-volume drainage as opposed to diagnose UL (18). During this study, whilst attempting maximal drainage, on average patients had 1.1 litres removed prior to spontaneous cessation of fluid or patients met criteria for discontinuation, mostly due to symptoms limiting further drainage, despite many having evidence of residual effusion (18). These volumes are similar to the volumes removed during initial drainage post-IPC insertion in our study and highlights that in many patients complete fluid evacuation during initial drainage is unachievable. Furthermore, the volumes removed on initial drainage with manometry measurements in our study compare favourably with those in previous thoracentesisbased manometry studies, and therefore should be comparable (10-12). Whilst patients had different amounts of fluid removed, rather than selecting a specific drainage volume for analysis, we opted to maximise our available data, as earlier cessation would potentially underestimate UL by being unable to identify those with a 'late' inflection point on a biphasic elastance curve. Unfortunately, due to the exploratory nature of this study we do not have information on the reasons for terminating drainage in patients.

Radiographic UL was assessed at day 10 post-insertion and compared to manometry performed 10 days prior. Theoretically patients with manometry indicative of UL may have subsequent expansion and thus not classified radiographically as substantial UL by day 10 . This would explain the false positive manometry results observed in our cohort in which later radiographic assessment of UL 
was undertaken compared to previous studies in which radiographs were performed sooner after manometry, and therefore false positive manometry results may not have been observed $(11,12)$. Likewise, patients with UL assessed at day 10 may have subsequent expansion with further drainage if followed up. However, whilst immediate postinsertion imaging was not available, due to air entrainment during insertion these images can incorrectly suggest UL. Furthermore, clinicians contemplating using talc via an IPC to manage MPE need an acceptable timepoint, balancing the requirement of adequate drainage allowing pleural apposition to facilitate effective talc pleurodesis, whilst minimising delay to intervention in this palliative cohort. Day 10, as used in IPC-Plus (7), is now a proven timepoint to assess UL and perform pleurodesis. In considering this, we felt it was an acceptable compromise between allowing regular, but not aggressive, drainage to facilitate full chest evacuation, with patients having approximately 4 litres on average drained between insertion and day 10 imaging. This avoids categorising slow-to-expand lungs, which may benefit from pleurodesis when adequately drained, as true UL, whilst also minimising significant delay to definitive pleurodesis. Previous studies which compare manometry with immediate post-drainage imaging may fail to delineate slow-to-expand and true UL $(11,12)$. Therefore, we feel the correlation between manometry at initial drainage and UL at day 10 is still of vital importance.

Chest radiography was used as our comparator to assess lung expansion. We acknowledge that UL may be difficult to define on chest radiography, with its inability to demonstrate pathology in three dimensions being particularly relevant and may lead to UL underestimation. These reasons may cause the poor inter-observer correlation seen when assessing radiographs for UL (23) and the varied rates of UL post-drainage in previous studies, which often use different diagnostic criteria of UL $(24,25)$. Whilst more sophisticated techniques exist to assess UL, for example interval CT scanning (26), this was felt to be neither practical nor reflective of what occurs in clinical practice for use in our current study. Furthermore most other studies have compared manometry with chest radiography, hence our study should be comparable to those $(11,12,16)$. In fact our study suggested higher rates of UL compared to those previous studies using single-thoracentesis, which may reflect our methodology of assessing radiographs after 10 days of ambulatory drainage, with prolonged fluid removal allowing better characterisation of UL.
Unfortunately, our sub-study was not powered to find a difference in pleurodesis success rate between those with full expansion versus partial UL in this manometric cohort. However this studies parent trial showed that the efficacy of pleurodesis was not impacted by the presence of a small degree of UL, defined using the same criteria for partial UL as used here, compared to those deemed to have fully expansile lungs, suggesting full lung expansion is not a prerequisite to effective pleurodesis in the context of an IPC (7).

Although in this study we analysed terminal elastance, previous studies often fail to specify how elastance is calculated from biphasic curves; meaning our results may not be directly comparable where unspecified calculation techniques were used. However, there is growing consensus that biphasic curves represent 2 processes, with terminal elastance more likely to reflect the point of abnormal pleural pathology, and hence be of more importance when interpreting elastance curves $(9,27)$.

\section{Conclusions}

This exploratory analysis, whilst showing significant differences in closing pleural pressure and terminal elastance in those with substantial UL, suggests that the predictive properties of manometry to detect UL are poorer than previously suggested. Based on these results, we cannot recommend the use of manometry at the time of IPC insertion to accurately predict those with substantial UL and guide the use of outpatient talc pleurodesis. However, there may be a role for closing pleural pressure, if used to facilitate safe drainage, in predicting patients who may have UL if unsafe pleural pressures are reached during drainage.

\section{Acknowledgments}

The authors would also like to thank Emma Keenan, Anna Morley, Natalie Zahan-Evans, Louise Stadon, Mohammed Munavvar, James Walters and Biswajit Chakrabarti for their contribution to this work.

Funding: None.

\section{Footnote}

Conflicts of Interest: All authors have completed the ICMJE uniform disclosure form (available at http://dx.doi. org/10.21037/jtd.2020.02.25). The authors have no conflicts of interest to declare. 
Ethical Statement: The authors are accountable for all aspects of the work in ensuring that questions related to the accuracy or integrity of any part of the work are appropriately investigated and resolved. Ethics approval for recruitment was obtained from the South Central (Oxford A) Research Ethics Committee (approval number: 12/ SC/0242).

Open Access Statement: This is an Open Access article distributed in accordance with the Creative Commons Attribution-NonCommercial-NoDerivs 4.0 International License (CC BY-NC-ND 4.0), which permits the noncommercial replication and distribution of the article with the strict proviso that no changes or edits are made and the original work is properly cited (including links to both the formal publication through the relevant DOI and the license). See: https://creativecommons.org/licenses/by-nc-nd/4.0/.

\section{References}

1. American Thoracic Society. Management of malignant pleural effusions. Am J Respir Crit Care Med 2000;162:1987-2001.

2. Roberts ME, Neville E, Berrisford RG, et al. Management of a malignant pleural effusion: British Thoracic Society Pleural Disease Guideline 2010. Thorax 2010;65 Suppl 2:ii32-40.

3. Clive AO, Jones HE, Bhatnagar R, et al. Interventions for the management of malignant pleural effusions: a network meta-analysis. Cochrane Database Syst Rev 2016;(5):CD010529.

4. Du Rand I, Maskell N. Introduction and methods: British Thoracic Society Pleural Disease Guideline 2010. Thorax 2010;65 Suppl 2:ii1-3.

5. Tremblay A, Michaud G. Single-center experience with 250 tunnelled pleural catheter insertions for malignant pleural effusion. Chest 2006;129:362-8.

6. Warren WH, Kalimi R, Khodadadian LM, et al. Management of malignant pleural effusions using the Pleur(x) catheter. Ann Thorac Surg 2008;85:1049-55.

7. Bhatnagar R, Keenan EK, Morley AJ, et al. Outpatient Talc Administration by Indwelling Pleural Catheter for Malignant Effusion. N Engl J Med 2018;378:1313-22.

8. Feller-Kopman D. Point: should pleural manometry be performed routinely during thoracentesis? Yes. Chest 2012;141:844-5.

9. Maldonado F, Mullon JJ. Counterpoint: should pleural manometry be performed routinely during thoracentesis? No. Chest 2012;141:846-8.
10. Salamonsen MR, Lo AKC, Ng ACT, et al. Novel use of pleural ultrasound can identify malignant entrapped lung prior to effusion drainage. Chest 2014;146:1286-93.

11. Lan RS, Lo SK, Chuang ML, et al. Elastance of the pleural space: A predictor for the outcome of pleurodesis in patients with malignant pleural effusion. Ann Intern Med 1997;126:768-74.

12. Heidecker J, Huggins JT, Sahn SA, et al. Pathophysiology of pneumothorax following ultrasound-guided thoracentesis. Chest 2006;130:1173-84.

13. Bhatnagar R, Kahan BC, Morley AJ, et al. The efficacy of indwelling pleural catheter placement versus placement plus talc sclerosant in patients with malignant pleural effusions managed exclusively as outpatients (IPC-PLUS): study protocol for a randomised controlled trial. Trials 2015;16:48.

14. Lee HJ, Yarmus L, Kidd D, et al. Comparison of pleural pressure measuring instruments. Chest 2014;146:1007-12.

15. Akulian J, Yarmus L, Feller-Kopman D. The Evaluation and Clinical Application of Pleural Physiology. Clin Chest Med 2013;34:11.

16. Boshuizen RC, Sinaasappel M, Vincent AD, et al. Pleural pressure swing and lung expansion after malignant pleural effusion drainage: the benefits of high-temporal resolution pleural manometry. J Bronchology Interv Pulmonol 2013;20:200-5.

17. Feller-Kopman D, Walkey A, Berkowitz D, et al. The relationship of pleural pressure to symptom development during therapeutic thoracentesis. Chest 2006;129:1556-60.

18. Lentz RJ, Lerner AD, Pannu JK, et al. Routine monitoring with pleural manometry during therapeutic largevolume thoracentesis to prevent pleural-pressure-related complications: a multicentre, single-blind randomised controlled trial. Lancet Respir Med 2019;7:447-55.

19. Galal M, El Halafawy A, Assal HH, et al. Pleural manometry in pleural effusion. Egypt J Chest Dis Tu 2016;65:415-9.

20. Huggins JT, Sahn SA, Gurung P, et al. Prevalence of Lung Entrapment in a Series of Forty Consecutive Patients with Malignant Pleural Effusions. Am J Respir Crit Care Med 2009;179.

21. Josephson T, Nordenskjold CA, Larsson J, et al. Amount drained at ultrasound-guided thoracentesis and risk of pneumothorax. Acta Radiol 2009;50:42-7.

22. Mynarek G, Brabrand K, Jakobsen JA, et al. Complications following ultrasound-guided thoracocentesis. Acta Radiol 2004;45:519-22.

23. Martin GA, Kidd AC, Tsim S, et al. Inter-observer 
variation in image interpretation and the prognostic importance of non-expansile lung in malignant pleural effusion. Respirology 2020;25:298-304.

24. Dresler CM, Olak J, Herndon JE 2nd, et al. Phase III intergroup study of talc poudrage vs talc slurry sclerosis for malignant pleural effusion. Chest 2005;127:909-15.

25. Davies HE, Mishra EK, Kahan BC, et al. Effect of an indwelling pleural catheter vs chest tube and talc pleurodesis for relieving dyspnea in patients with

Cite this article as: Halford PJ, Bhatnagar R, White P, Haris M, Harrison RN, Holme J, Sivasothy P, West A, Bishop LJ, Stanton AE, Roberts M, Hooper C, Maskell NA. Manometry performed at indwelling pleural catheter insertion to predict unexpandable lung. J Thorac Dis 2020;12(4):1374-1384. doi: $10.21037 /$ jtd.2020.02.25 malignant pleural effusion: the TIME2 randomized controlled trial. JAMA 2012;307:2383-9.

26. Terra RM, Junqueira JJM, Teixeira LR, et al. Is full postpleurodesis lung expansion a determinant of a successful outcome after talc pleurodesis? Chest 2009; 136:361-8.

27. Huggins JT, Maldonado F, Chopra A, et al. Unexpandable lung from pleural disease. Respirology 2018;23:160-7. 